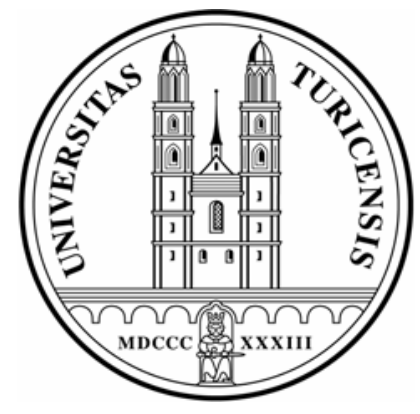

Institute for Strategy and Business Economics

University of Zurich

Working Paper Series

ISSN I660-1157

Working Paper No. 56

The Skill-Weights Approach on Firm Specific Human Capital:

Empirical Results for Germany

Uschi Backes-Gellner and Johannes Mure

April 2005 


\title{
The Skill-Weights Approach on Firm Specific Human Capital: Empirical Results for Germany*
}

\author{
Uschi Backes-Gellner** \\ University of Zurich, Switzerland
}

\author{
Johannes Mure*** \\ University of Zurich, Switzerland
}

Working Paper, Zurich, April 2005

\begin{abstract}
In a recent paper Ed Lazear (2004) proposed the so called skill-weights view of firmspecific human capital. According to his theory all single skills are general but each firm may require a different combination of these single skills. The purpose of our paper is to test Lazear's model using a large and very detailed data set, the BIBB/IAB Qualification and Career Survey. The paper focuses on firms' investments in human capital, which according to the skill-weights approach should depend on the specificity of the firm's skill combination, on the breadth of the skill bundle, on the thickness of the external labor market and on the probability of separation. We estimate OLS regressions and poisson regression for count data. We find that all implications are borne out in the data.
\end{abstract}

Keywords: Skill-Weights Approach, Firm-Specific Training, Training in Germany JEL Classification: M 5, M 12, M 53

\footnotetext{
* For comments and discussions we are grateful to the participants of the IAAEG Network meeting at the university of Trier, the personnel economics colloquium at the University of Konstanz and the research seminar at the University of Zurich. The views expressed herein and all remaining errors are those of the authors.

** Professor for Business and Personnel Economics, University of Zurich, Plattenstrasse 14, CH - 8032 Zürich, Tel: +41-1-6344281, Email: backes-gellner@isu.unizh.ch.

*** University of Zurich, Institute for Strategy and Business Economics (ISU), Plattenstrasse 14, CH - 8032 Zürich, Tel: +41-16344276, Email: johannes.mure@isu.unizh.ch.
} 


\section{The Skill-Weights Approach on Firm Specific Human Capital: Empirical Results for Germany}

\section{Introduction}

In a recent paper Ed Lazear (2004) proposed the so called skill-weights view of firmspecific human capital. His main idea is that unlike in traditional human capital theory all skills, taken alone, are general. But the particular combination of skills required in one firm may be firm specific in the sense that it may be unlikely to find the same combination of skills in any other firm. Based on a simple skill-weights earning function Lazear cannot only reproduce the implications of the traditional view of firmspecific human capital which are well tested in the empirical literature, but he can also derive a number of implications that go beyond the traditional human capital approach, particularly regarding the tenure effect in wage regressions.

The purpose of our paper is to test Lazear's model using a large and very detailed data set on training and employment in Germany, the so-called BIBB/IAB Qualification and Career Survey. The main advantage of this data set is the broad range of questions including different types of training, a long list of job requirements, detailed job history information and earnings, which perfectly qualify the data set to test major parts of the Lazear model. We particularly focus on investment in human capital of employers and - following Lazear's model - analyze under which conditions employers are more likely to invest in the human capital of their employees. According to Lazear's model the specificity of the skill combination, the range of the skill bundle, the thickness of the external labor market and the probability of separation should determine firm's investment in human capital. We find that all implications are borne out in our data.

The paper is organized as follows. In Section 2 we use Lazear's model to derive testable implications on the amount of training offered by firms. In Section 3 we introduce the data set and explain how the explanatory variables are built and in section 4 we present empirical results using OLS and poisson regression model for count data. We conclude with a short summary and implications for future research in Section 5. 


\section{The Skill-Weights Approach: Basic Idea and Testable Implications}

In the basic skill-weights model there are only two skills and two periods. Both skills are general, i.e. they are used at other firms as well, but the combination of skills varies from firm to firm. Workers invest in either skill in the first period and receive payoffs in the second period. So, in the first period workers decide to acquire a particular amount of skill $A$ and $B$, at cost $C(A, B)$, which determines their payoff in the second period. At firm $i$ their payoff is determined according to the following earnings function (Lazear 2004: 3):

$$
y_{i}=\lambda_{i} A+\left(1-\lambda_{i}\right) B
$$

$\lambda_{i}$ is the relative weight of skill $\mathrm{A}$ in firm $i$, which may be quite different from skill $\mathrm{A}$ 's relative weight in any other firm $j$. The workers' investment problem is to choose how much to invest in $A$ and $B$, given that he remains at the initial firm with probability $q$, or loses his job with probability $(1-q)$, in which case he has to move on to another firm with skill weights $\lambda_{j}$. So workers choose to invest in a combination of skills A and B in period 1 in a way that maximizes their expected income in period 2. Solving the standard maximization problem Lazear shows that investment is a weighted average of the inside and outside skill-weights where weights are dependent on the probability of a separation (Lazear 2004: 7). The intuition is as follows: If a worker knows for sure that he will stay in the initial firm only the skill weight inside this initial firm matters. On the contrary, if a worker is certain to leave the firm, only skill weights outside the firm matter. However, ex ante that worker does not know in which particular firm he may get his next job, so he has to make his investment decision according to the expected skill weight $\bar{\lambda}$.

As Lazear (2004: 13ff) further shows that the expected wage loss depends on the difference $\left(\lambda_{i}-\bar{\lambda}\right)$, i.e. on the firm being very typical in its skill requirements (with weights close to market average) or very untypical (with weights very different from market average). The more idiosyncratic a firm is in its skill requirements (i.e. the larger $\left(\lambda_{i}-\bar{\lambda}\right)$ is), the larger would be the loss of a worker if he had invested according 
to the skill weights $\lambda_{i}$ in the initial firm. So it depends on $q$, whether workers are more or less willing to invest in the firm-specific combination of skills $\lambda_{i}$. Large differences $\left(\lambda_{i}-\bar{\lambda}\right)$ make it unlikely that the worker will be worth more for another firm than for the initial firm. A voluntary move from the current employer is restricted to a small number of firms where the difference $\left(\lambda_{i}-\bar{\lambda}\right)$ is similar to the one in the initial firm. So under this skill-weights view, it is only natural that the firm would pay for at least part of the human capital investment because a worker who later on wants to leave the firm will almost certainly fail to find another employer that needs the skills in the same combination. Since workers are unwilling to bear the full cost for training with very specific skill weights $\lambda_{i}$, Lazear concludes that the firm may bear some or even most of the cost of these skills.

According to Lazear's skill-weights we identify five empirically testable parameters that should drive the extent of a firm's willingness to bear these costs of training.

\section{Idiosyncratic Firms}

Firms pay for a larger share of training when their particular skill-weights are very specific or idiosyncratic because worker's are less willing to invest in training the more idiosyncratic the skill-weights are. A worker's loss in earnings when involuntarily moving on to another firm depends on the degree of specificity $\left(\lambda_{i}-\bar{\lambda}\right)$, so the more idiosyncratic a firm's skill requirements are, the larger is the worker's expected loss in earnings. Therefore, if an idiosyncratic firm wants the worker to invest according to its idiosyncratic skill requirements it has to and is willing to pay for the training (Lazear 2004: 32). This leads us to the first testable implication: The more idiosyncratic the skill requirements of a firm are, the higher is the probability of firm sponsored training in (general) skills.

\section{Probability of Separation}

Given a degree of specificity $\left(\lambda_{i}-\bar{\lambda}\right)$, a worker's expected loss rises with the probability of separation (Lazear 2004: 7f), so other things being equal he is less willing to invest in training with specific skill combinations. If the firm wants the worker to invest in its idiosyncratic skill combination it has to bear at least part of the 
cost. So other things being equal we expect the firms to invest more in training the higher the probability of separation.

\section{Variance of the Skill-Weights Distribution $f(\lambda)$}

However, investment in training does not only depend on the expected skill weights $\bar{\lambda}$ but also on other parameters of the distribution $f(\lambda)$. Given a value for $\bar{\lambda}$ there may still be differences in the variance. If a worker is trained in an occupation that is well defined, the skill weights should be about the same in any firm in the labor market, so the variance and the risk of the worker is very low. If, however, a worker is trained in a job that is not within a well defined occupation, the skill weights outside the initial firm may vary widely and the risk of not finding a firm that is similar to the initial firm is large. Therefore, we expect workers to be less willing to invest in training in occupations or in firms that offer jobs that are not well defined, which means that the firms have to bear a higher share of the costs in these situations. So all else being equal, we expect the firms to invest more in training in poorly defined occupations and jobs.

\section{Market Thickness}

Fourthly, Lazear shows that investment in training is determined by market thickness. An increase in market thickness is defined as allowing more job offers (Lazear 2004: 31). A thicker market is represented as one where the worker picks not only one but two, three or even more draws of $\lambda$, so he has the option to choose among a broader variety of job offers. Of course, he selects the job that best suits his prior investment strategy. Thus, the result for a worker with several draws can never be worse than the result for a worker with a single draw and will very likely be better since he only needs one job offer that is better than the one in the single draw case. As market thickness increases, investments that would otherwise be viewed as firm-specific become more and more general. The intuition is that as the number of offers increases, workers are more likely to find another firm or job that requires skills in the same (or similar) combination as in the original firm. In contrary, when markets are thin, the worker might have to settle for a firm that makes little use of his particular skills or skill combination. Therefore, in a thick market a worker is more willing to undertake 
idiosyncratic training investments and we expect the firms to invest less with an increase in market thickness. ${ }^{1}$

\section{Number of Skills Required}

Since human capital investments and skill requirements may not only differ with regard to the weight given to two different skills A and B but also with regard to how many different skills a person is required to have, the simple model would have to be modified by adding further skills $\mathrm{C}, \mathrm{D}$ etc. The more skills a worker acquires in his initial firm, the more difficult it is for him to find a job with exactly the same skill combination because each skill adds as another constraint. The worker might have to settle for a job that requires fewer skills than his initial job in order to find an adequate combination of skills. This is particularly true in industries where the skill distribution is strongly skewed, i.e. with few firms requiring a large number of skills and most firms calling for only a very small selection out of a whole range of skills. So the worker might have to settle for a job where he uses only a small part of his initial skills and looses the rest of his skills. Consequently, all else being equal, workers will be less willing to invest in training in industries where the skill distribution is very skewed, and we expect firms to invest more in training if the skill distribution is more skewed.

In the following we will test our implications using a large German data set on training and skill requirements.

\section{Data}

Our empirical analysis is based on a dataset which is a 0.1 percent sample of the working population in Germany conducted verbally and computer based between October 1998 and March 1999. The data are from the so called "BIBB/IAB Qualification and Career Survey". The dataset was gathered by the Federal Institute for Vocational Training (BIBB), Berlin, in collaboration with the Federal Employment Service`s Institute for Employment Research (IAB), Nuremberg. It is representative for

\footnotetext{
${ }^{1}$ Other empirical studies for Italia (Brunello/de Paola 2004) and the UK (Brunello/Gambarotto 2004) underline that training investment not only depends on firms' characteristics but also on regional labor market thickness.
} 
Germany and contains retrospective information on the educational and occupational carrers. We restrict our analysis to individuals between 16 years (the minimum age for leaving school and entering the labor market) and 65 years (the mandatory age of retirement for paid employees). Furthermore we exclude all civil servants (facing no layoff risk) and all self-employed.

The survey contains a large set of questions about the workers' and employers' training activities. The extent of employer financed training is at the heart of our empirical investigation. Among other, the survey asks what kind of training the worker received during the last two years. As our dependent variable we use the number of training measures which were financed "mostly" or "entirely" by the employer. Interviewees reported between zero and five employer financed training measures within the last two years (1997-1998). In our sample $(\mathrm{N}=13,604)$ the average number of training measures over those two years is 0,95 - a number well in line with evidence from official statistical data of the German work force survey (Kuwan/Thebis 2003).

In our regression models we use a standard set of control variables such as age, tenure, different human capital variables (schooling, apprenticeships, degrees as a master craftsman, university degrees), sex and industries in addition to five explanatory variables, which are specified as follows.

\section{Idiosyncratic firms (highly specific skill weights)}

The degree of specificity of the skill weights is measured by two variables. The first is a dummy-variable which reflects whether the interviewee is - in his own view - easily replaceable at his current job or not. $59 \%$ of the interviewees think that they are not easily replaceable. We assume that if a worker thinks he is not easily replaceable he uses fairly specific skills on his job that cannot be found elsewhere in the internal or external labor market. The second variable to measure the degree of specificity is the number of voluntary job changes in the past (never, once, twice or more); on average the number of voluntary job changes was 1,59. In accordance with the skill-weights approach (and standard human capital theory) we assume that workers only leave their previous employer if the outside wage offer exceeds his initial wage. So the worker only leaves his previous employer if he receives an outside offer from a firm which has a value of $\lambda_{j}$ that exceeds $\lambda_{i}$ because this increases his income (Lazear 2004: 12). 
However, higher values of $\lambda_{j}$ also mean an increase in the difference to $\bar{\lambda}$ and therefore, a higher degree of specificty. In other words, with every job change the degree of specificity increases.

\section{Probability of Separation}

We measure the probability of an involuntary and exogenously determined job loss by a dummy variable that states whether the firm is - in the worker's view - in a bad economical situation (1) or in good shape (0) (mean: 0.19). ${ }^{2}$

[Table 1 near here]

\section{Variance of skill weights distribution}

In our data set the respondents were asked to report up to 18 different skills that are required to do their current job. As a proxy for the variance of the skill weight distribution noise in the external labor market we use the standard deviation of required skills in 49 industries. We assume that the higher the standard deviation of the number of skills used in an industry the higher is the variance of the skill weights distribution. Some industries have very homogenous skill needs with low standard deviations. These industries, for exemple hairdressers, retail markets, etc., have a low variance in skill weights. In other industries, such as precision mechanics, insurances, etc., skills requirements are less homogenous, so the variance in the skill weights distribution is assumed to be larger. The mean over all industry specific standard deviations is 2.51 but they vary substantially from industry to industry. ${ }^{3}$

\section{Market thickness}

According to Lazear, market thickness should measure the number of job offers a worker receives in the regional and occupational specific external labor market. The number of job openings therefore seems to be a good proxy for job market thickness. Since it is not clear ex ante which one is the relevant labor market for any given worker

\footnotetext{
${ }^{2}$ Unfortunately, in our data set there is not enough information on the economic situation of individual firms to create a metrical variable. Also, a variable where the interviewee rates his personal layoff risk is not used because of strong endogeneity problems: Workers which reported low layoff risks were trained strongly in the last two years whereas the theoretical model demands for exogenous probability of a layoff.

3 For further industries see table A1 in the appendix.
} 
we use two different variables to measure labor market thickness: firstly, we focus on regional labor market thickness and secondly we look at industry specific labor market thickness. Both variables are based on official German labor market statistics (Bundesanstalt für Arbeit 1998). Regional labor market thickness is the ratio of job offers registered relative to total labor force per region (Bundeslaender). Industry specific labor market thickness is the ratio of job offers relative to all workers in the respective industry.

\section{Number of skills required}

Workers are expected to be less willing and firms are expected to be more willing to invest in training in industries where the skill distribution is more skewed. In industries with highly skewed skill distribution we have few firms requiring a large number of skills and most firms calling for only a very small selection out of a whole range of skills. We measure the skewness of the distribution of required skills within industries by the degree of asymmetry. The higher is the degree of asymmetry, the more skewed is the distribution towards a small number of skills, the higher should be firm's investment.

\section{Method and Results}

In order to test our hypotheses we apply two different estimation methods to our $\mathrm{N}=13,604$ employees in the sample. Firstly, we use OLS estimates with number of employer financed training measures as a dependent variable. This variable spans from zero to five, meaning that we have six values on a metric scale. OLS results with robust standard errors are shown in table 2, 'Model 1'. Secondly, we apply a poisson maximum likelihood regression model to account for the limited range of our dependent variable, which only consists of very few values including zero but no negative integer values (Wooldridge 2003: 573f.). Poisson regression results are given in table 2, 'Model 2'. 
Since the estimated coefficients of poisson regression cannot be interpreted easily we will use the OLS results for our interpretations. However, as can be seen in table 2, the results and significance of model 1 are very similar to those of model 2.

The empirical results reported in table 2 support the skill-weights view of firm specific skills put forward by Lazear (2004). To start with the control variables the number of employer-financed training is higher for men and increases both with higher schooling and with the level of former qualifications. These findings, as well as the fact that training increases with firm size, are consistent with previous empirical papers on training quantities and intensities (e.g. Pischke 2001). Furthermore, we find higher employer financed training in East German regions than in West German regions. Also a positive age effect within a negative quadratic function is common knowledge and consistent with other studies.

The estimated results demonstrate that both variables measuring the degree of specificity are positively correlated with employers` training investments as expected in our hypotheses. The dummy variable indicating whether the worker is not replaceable at his current job is statistically highly significant at the $1 \%$-level. The second variable reflecting specificity was the number of job changes. As expected, the variable is positive and significant. Also, the probability of separation is as expected significantly positively correlated with the firms` training investments.

[Table 2 near here]

Futhermore, also in accordance to our hypotheses, the employers` training investments increase with the variance in the distribution of the required skills. Employers invest more in training in industries where the skill requirements distribution have a larger variance. We also find the skewness is significantly positively correlated with employer financed training (standard deviation and mean of the skill distribution held constant). Last but not least, the estimated coefficients of both market thickness variables are negative and highly significant as expected. If the number of job offers in a region or in an industry increases, then the firms' training investments decrease. Carefully 
interpreted, the impact of the regional market thickness is somewhat smaller then industry specific labor market thickness.

\section{Summary and Conclusions}

The purpose of our paper is to present a first empirical test of the skill-weights approach on firm-specific human capital developed by Lazear (2004). We concentrate our analysis on training investments of employers. According to Lazear's model we expect the specificity of the skill combination, the variance and skewness of the industry wide skill distribution, the labor market thickness and the probability of separations to determine a firm's investment in human capital. We find that all implications are borne out in our data.

The higher the probability of a separation, i.e. the higher the individual firm's risk of a plant shut down, the higher is the employer's investment in training. Under standard human capital theory, this finding is not obvious because given a very uncertain time horizon one would not expect a company to be willing to invest in their employees' human capital.

We also find, that the more often workers changed their jobs in the past, i.e. the higher the degree of specificity of their skill weights, the higher is the employers investment in training because workers become less and less willing to invest in ever more specific skill combinations. According to standard human capital theory this result (job changes raising employers investment in training) is somewhat surprising because with every job change the worker destroys his entire firm specific human capital and is left with only general skills. According to standard human capital theory there would be no reason for an employer to invest more and more in such a worker. However, analysing this phenomenon with the skill-weights approach, there is a clear intuition. A workers skill portfolio becomes more specific just because of the job changes. His individual skill combination deviates more and more from the average skill combination on the external labor market, which leads to higher investments of employers. 
Thirdly, if a worker is trained in a job that is not within a well defined occupation, the firm has to bear a higher share of the training costs. The phenomenon that a more precise definition of occupations has a strong positive effect on employer-financed training is not obvious under the traditional view of firm-specific training. But according to the skill-weights approach, the intuition is more obvious. The worker is less willing to invest in training if the skill weights outside the initial firm vary widely and the risk of not finding a firm with similar skill weights than the initial firm is high. If on the other hand, a worker is trained in a job within a well defined occupation, the skill weights outside the initial firm are very likely to be similar to the initial firm and therefore the employee is willing to bear a larger proportion of his training costs.

An increasing labor market thickness, i.e. a larger number of job offers on the external labour market diminishes employers' training investments. Under the traditional notion of specific human capital, the thickness implication is less obvious, if present at all. According to the skill-weights view an increasing number of jobs on the external labor market make it more likely for workers to find a new firm or job requiring the same skill combination as in the initial firm. So the worker is more willing to invest in idiosyncratic training and the firms have to invest less.

In industries where few firms need a large number of skills but most of the firms need only a very small number out of a broad range of skills, firms are more likely to invest in training because employees are very unwilling to invest in firm specific skills in such a situation. As a consequence the employer has to invest more in their employee's human capital. 


\section{References}

Brunello, Georgio; de Paola, Maria (2004): Training and the Density of Economic Activity: Evidence from Italy. IZA Discussion Paper 1173.

Brunello, Georgio; Gambarotto, Francesca (2004): Agglomeration Effects on Employer-Provided Training: Evidence from the UK. IZA Discussion Paper 1055.

Kuwan, Helmut; Thebis, Frauke (2003): Berichtssystem Weiterbildung VIII. Bundesministerium für Bildung und Forschung (Ed.). Berlin (2003).

Lazear, Edward P. (2004): Firm-Specific Human Capital: A Skill-Weights Approach. NBER Working Paper Nº 9679 - revised version - (2004).

Pischke, Jörn St. (2001): Continuous training in Germany. Journal of Population Economics 14(2001): 523-548.

Bundesanstalt für Arbeit (1998): Amtliche Nachrichten der Bundesanstalt für Arbeit (ANBA). Nuremberg (1998).

Wooldridge, J.M. (2003): Introductory Econometrics. A Modern Approach. Mason/Ohio: Thomson/South-Western (2003). 


\section{Dependent variable:}

Extent of employer financed training

Explanatory variables:

Workers specificity degree

Exogenous lay-off risk

Characteristics of $\lambda$-distribution

Market thickness
0 to five trainings

Mean

0.95

Standdev

1.14

$\begin{array}{ccc}\begin{array}{c}\text { Expected } \\ \text { effect } \\ + \\ +\end{array} & 0.59 & 0.49 \\ + & 1.59 & 1.40 \\ + & 0.19 & 0.39 \\ + & 2.51 & 0.27 \\ - & 1.39 & 0.41 \\ - & 0.14 & 0.04 \\ & 0.14 & 0.14\end{array}$

not replaceable at current job (Dummy; 1=not replaceable) number job changes

(metrical)

lay-off risk

(Dummy; 1=high risk)

standard deviation in skill requirements

(metrical)

skewness in skill requirements

(metrical)

regional market thickness

(metrical)

industrial market thickness

(metrical)

Control variables: age, age ${ }^{2}$, tenure, tenure ${ }^{2}$, Experience, weekly working time, dummy for Eastern Germany, male dummy, 6 human capital dummies, 6 working level dummies, blue collar and white collar dummy, 6 firm size dummies, 9 income dummies, 49 industry dummies. 
Table 2: The Extent of Employer Financed Training

Model 1

Model 2

(OLS regression)

Workers specificity degree

not replaceable at current job

$\begin{array}{ll}0.0586 * * * & 0.0856^{* * * *} \\ (0.0191) & (0.0209) \\ 0.0168^{* *} & 0.0293 * * * \\ (0.0081) & (0.0091)\end{array}$

Exogenous lay-off risk

lay-off risk

$0.0437 *$

$0.0474 *$

$(0.0227)$

$(0.0245)$

Characteristics of $\lambda$-distribution standard deviation in skill requirements

$\begin{array}{ll}0.5512 * * * & 0.5820 * * * \\ (0.1092) & (0.1837) \\ 0.4976 * * * & 0.6376 * * \\ (0.1256) & (0.2545)\end{array}$

Market thickness

$-0.0116^{* * *}$

$-0.0115 * * *$

regional market thickness

$(0.0041)$

$(0.0043)$

industrial market thickness

$-0.0289$

$-0.0422^{*}$

(0.0186)

(0.0253)

Const.

$-1.9391 * * *$

$\mathrm{N}$

13.604

$4.8865 * * *$

Adjusted R $\mathrm{R}^{2}$ Pseudo R

$28.39 \%$

13.604

$13.69 \%$

Significance level: $* * *=1 \%, * *=5 \%, *=10 \%$

Estimated robust standard errors are in parantheses below coefficients 


\section{Appendix}

Table A1: Variable "Skills Required"

\begin{tabular}{|c|c|c|c|c|}
\hline industry & $\begin{array}{l}\text { number of } \\
\text { observations }\end{array}$ & mean & std. deviation & Min \\
\hline Landwirt & 455 & 1.828571 & 2.053593 & 0 \\
\hline Haushalt & 234 & 1.495726 & 2.286831 & 0 \\
\hline Bergbau & 199 & 2.487437 & 2.407604 & 0 \\
\hline Chemie & 945 & 3.063492 & 2.806279 & 0 \\
\hline ErdeGlas & 236 & 2.110169 & 2.422532 & 0 \\
\hline Eisen & 450 & 2.282222 & 2.386468 & 0 \\
\hline Stahlbau & 402 & 2.281095 & 2.187722 & 0 \\
\hline Maschinenbau & 974 & 3.155031 & 2.81305 & 0 \\
\hline Automobil & 991 & 2.691221 & 2.534113 & 0 \\
\hline Schiffflugz & 86 & 2.953488 & 2.068856 & 0 \\
\hline Bueromasch & 82 & 3.963415 & 3.048761 & 0 \\
\hline E technik & 853 & 3.201641 & 2.686105 & 0 \\
\hline Feinmechanik & 169 & 3.213018 & 2.994371 & 0 \\
\hline Metallwaren & 333 & 1.882883 & 2.279051 & 0 \\
\hline $\mathrm{Bau}$ & 2096 & 2.194179 & 2.265858 & 0 \\
\hline Holz & 441 & 2.20181 & 2.330157 & 0 \\
\hline Papier & 138 & 3.101449 & 2.940505 & 0 \\
\hline Druck & 241 & 2.709544 & 2.321698 & 0 \\
\hline Leder & 36 & 1.194444 & 1.527265 & 0 \\
\hline Textil & 319 & 1.780564 & 2.183874 & 0 \\
\hline Nahrung & 641 & 1.847114 & 2.130514 & 0 \\
\hline Reinigung & 107 & 1.056075 & 1.912382 & 0 \\
\hline Frisoer & 233 & 1.412017 & 1.645849 & 0 \\
\hline SonstIuH & 1025 & 2.718049 & 2.574574 & 0 \\
\hline Einzelhandel & 1458 & 1.94513 & 2.207433 & 0 \\
\hline Kaufhaus & 1149 & 1.890339 & 2.105283 & 0 \\
\hline Tankstelle & 158 & 1.64557 & 1.820184 & 0 \\
\hline Versandhaus & 84 & 2.285714 & 2.422641 & 0 \\
\hline Grosshandel & 874 & 2.866133 & 2.599087 & 0 \\
\hline Handelsvertret & 98 & 3.418367 & 2.651292 & 0 \\
\hline SonstHandel & 351 & 3.156695 & 3.07821 & 0 \\
\hline Post & 544 & 2.615809 & 2.510642 & 0 \\
\hline Bahn & 253 & 2.849802 & 2.250478 & 0 \\
\hline Reisen & 305 & 2.590164 & 2.357638 & 0 \\
\hline Spedition & 354 & 2.358757 & 2.562222 & 0 \\
\hline Banken & 625 & 4.1056 & 2.582309 & 0 \\
\hline Versicherung & 338 & 4.026627 & 2.779087 & 0 \\
\hline Hotel & 568 & 1.875 & 2.507177 & 0 \\
\hline Krankenhaus & 1790 & 2.53743 & 2.357272 & 0 \\
\hline Arztpraxen & 570 & 2.785965 & 2.243478 & 0 \\
\hline Freiberuflerbuer & 544 & 3.680147 & 2.645524 & 0 \\
\hline Schule & 2256 & 3.887411 & 2.808713 & 0 \\
\hline OeffentlVerw & 2739 & 3.519898 & 2.716832 & 0 \\
\hline Verbaende & 645 & 3.29147 & 2.672962 & 0 \\
\hline Rundfunk & 312 & 3.173077 & 2.564069 & 0 \\
\hline Sport & 120 & 2.075 & 2.24979 & 0 \\
\hline Energie & 238 & 3.256303 & 2.710633 & 0 \\
\hline
\end{tabular}


Muell

SonstDienstl

125

1461
2.2

3.101985
2.729764

2.788652
14

15

STATA 8.1 
